\title{
HUBUNGAN KEBIASAAN MAKAN PAGI DENGAN KEJADIAN ANEMIA PADA MURID SD NEGERI 3 MANADO
}

\author{
${ }^{1}$ Erina Utami Tandirerung \\ ${ }^{2}$ Nelly Mayulu \\ ${ }^{2}$ Shirley E. S. Kawengian \\ ${ }^{1}$ Kandidat Skripsi Fakultas Kedokteran Unsrat Manado \\ ${ }^{2}$ Bagian Ilmu Gizi Fakultas Kedokteran Unsrat Manado \\ Email: erina_tandirerung@yahoo.com
}

\begin{abstract}
Anemia is a global public health problem in developing and developed countries with its major consequences for human health and the economic and national development. Anemia can occur at all stages of the life cycle, but it is more prevalent in pregnant women and children. Anemia in children due to lack of nutritional diet has bad impacts on their health, growth, and immune systems. The main causes of nutritional anemia are the insufficient iron ingestion, low iron absorption, and diet which mainly consists of rice and less diverse menu. Breakfast habits fall into one of the thirteen basic messages of balanced nutrition. The benefit of having breakfast for school children is that it can improve their concentration to study and to understand their lessons, resulting in improvement of their learning achievement. Besides that, breakfast plays some important roles in fulfilling the balanced nutrition in children. The purpose of this study was to find out the relationship between breakfast habits and anemia incidence among students of SD Negeri 3 Manado. This was an analytical cross-sectional study. The results showed that of 83 students, 58 students $(69.9 \%)$ had habits of having breakfast and 74 students $(89.2 \%)$ were not anemic. Analytical results obtained $P$-value $=0.019(\leq 0.050)$. Conclusion: there was a significant relation between breakfast habits and anemia incidence among the students of SD Negeri 3 Manado.

Key words: breakfast habits, children, anemia
\end{abstract}

\begin{abstract}
Abstrak: Anemia merupakan masalah kesehatan masyarakat global di negara berkembang maupun negara maju dengan konsekuensi yang besar bagi kesehatan manusia serta pembangunan nasional dan ekonomi. Anemia dapat ditemukan pada setiap tahap siklus hidup, namun lebih menonjol pada wanita hamil dan anak-anak. Anemia pada anak-anak akibat kurang gizi dapat berdampak buruk pada kesehatan, pertumbuhan, dan sistem imun. Penyebab utama anemia gizi ialah konsumsi zat besi yang tidak cukup, absorbsi zat besi yang rendah, dan pola makan yang sebagian besar terdiri dari nasi dan menu yang kurang beraneka ragam. Kebiasaan makan pagi termasuk dalam salah satu dari 13 pesan dasar gizi seimbang. Bagi anak sekolah, makan pagi dapat meningkatkan konsentrasi belajar dan memudahkan menyerap pelajaran yang akan meningkatkan prestasi belajar. Makan pagi juga sangat berperan terhadap pemenuhan gizi seimbang pada anak. Tujuan penelitian ini untuk mengetahui hubungan antara kebiasaan makan pagi dengan kejadian anemia pada murid SD Negeri 3 Manado. Penelitian ini merupakan suatu penelitian cross-sectional yang bersifat analitik. Hasil penelitian menunjukkan bahwa dari 83 murid, 58 murid $(69,9 \%)$ memiliki kebiasaan makan pagi dan 74 murid $(89,2 \%)$ yang tidak anemia. Hasil analisis diperoleh nilai $P=0,019(\leq 0,050)$. Simpulan: terdapat hubungan bermakna antara kebiasaan makan pagi dengan kejadian anemia pada murid SD Negeri 3 Manado.
\end{abstract}

Kata kunci: kebiasaan makan pagi, anemia, anak-anak 
Masalah gizi disebabkan oleh banyak faktor yang saling terkait baik secara langsung maupun tidak langsung. Secara langsung status gizi seseorang dipengaruhi oleh adanya penyakit infeksi dan tidak cukupnya asupan gizi baik kuantitas maupun kualitas, sedangkan secara tidak langsung dipengaruhi oleh jangkauan dan kualitas pelayanan kesehatan, pola asuh anak yang kurang memadai, kurang baiknya kondisi sanitasi lingkungan, serta rendahnya ketahanan pangan di tingkat rumah tangga. ${ }^{1}$

Anemia ditandai oleh rendahnya konsentrasi hemoglobin $(\mathrm{Hb})$ atau nilai ambang batas hematokrit yang disebabkan oleh rendahnya produksi sel-sel darah merah (eritrosit) dan $\mathrm{Hb}$, meningkatnya kerusakan eritrosit (hemolisis), atau kehilangan darah yang berlebihan. ${ }^{1}$

Menurut WHO, prevalensi anemia di seluruh dunia pada anak pra sekolah 47,4\%; anak usia sekolah $25,4 \%$; wanita hamil $41,8 \%$; wanita tidak hamil $30,2 \%$; pria dewasa $12,7 \%$; dan usia tua $23,9 \%$.

Secara umum, terdapat tiga penyebab anemia defisiensi zat besi, yaitu: 1) kehilangan darah secara kronis (dampak perdarahan kronis) seperti pada penyakit ulkus peptikum, hemoroid, infestasi parasit, dan proses keganasan; 2) asupan zat besi dan penyerapan yang tidak adekuat; dan 3) peningkatan kebutuhan zat besi untuk pembentukan sel darah merah yang lazim berlangsung pada masa pertumbuhan bayi, pubertas, kehamilan, dan menyusui. ${ }^{4}$

Defisiensi besi merupakan defisiensi gizi yang paling umum terdapat, baik di negara maju maupun negara berkembang. Defisiensi besi terutama menyerang golongan rentan seperti anak-anak, remaja, ibu hamil dan menyusui, serta pekerja berpenghasilan rendah. Defisiensi besi juga merupakan penyebab anemia yang paling sering ditemukan dan paling prevalen pada anak-anak berusia 6-24 bulan.

\section{METODE PENELITIAN}

\section{Jenis penelitian}

Jenis penelitian yang dilakukan ialah observasional analitik dengan pendekatan cross-sectional study.

\section{Tempat dan waktu Penelitian}

Penelitian dilaksanakan pada bulan Desember 2011 sampai dengan Januari 2012 di SD Negeri 3 Kelurahan Wawonasa Manado yang merupakan wilayah kerja Puskesmas Wawonasa dan dilakukan pada

\section{Populasi dan sampel}

Populasi pada penelitian ini terdiri dari murid-murid kelas 4, 5 dan 6 SD Negeri 3 Manado yang berjumlah 344 orang. Sampel merupakan bagian dari populasi. Jumlah sampel dalam penelitian ini ditentukan berdasarkan rumus besar sampel (Notoatmodjo, 1998) sebagai berikut:

$$
\mathrm{n}=\frac{\mathrm{N}}{1+\mathrm{N}(\mathrm{d})^{2}}
$$

Keterangan :

$$
\begin{aligned}
& \mathrm{n}=\text { Jumlah sampel } \\
& \mathrm{N}=\text { Jumlah populasi } \\
& \mathrm{d}=\text { Konstanta yang dipakai }(0,1)
\end{aligned}
$$

Jumlah populasi $(\mathrm{N})=344$ murid dan $\mathrm{d}=0,1$ sehingga diperoleh jumlah sampel sebanyak 75 murid, yang kemudian ditambahkan 10\% menjadi 83 murid. Cara pengambilan sampel dilakukan secara simple random sampling.

\section{Variabel penelitian}

Variabel bebas dalam penelitian ini ialah kebiasaan makan pagi, sedangkan variabel terikat anemia.

\section{Definisi operasional}

Makan pagi merupakan suatu kebiasaan anak sekolah yang dapat meningkatkan konsentrasi belajar. Kebiasaan makan pagi dalam penelitian ini ialah kebiasaan anak untuk makan/sarapan pagi berupa makanan pokok sebelum berangkat ke sekolah. Terdapat dua kategori mengenai makan pagi, yaitu: mempunyai kebiasaan makan pagi bila dalam seminggu minimal tiga kali makan pagi dan satunya lagi tidak mempunyai kebiasaan makan pagi bila tidak sama sekali atau kurang dari tiga kali dalam seminggu. 
Anemia adalah suatu keadaan dimana kadar hemoglobin pada anak umur 6-14 tahun kurang dari 11,5 g/dL (kriteria WHO tahun 2001).

Pemeriksaan hemoglobin dilakukan dengan menggunakan metode Sahli.

\section{Cara pengumpulan data}

\section{Angket atau kuesioner}

Daftar pertanyaan dibuat secara berstruktur dengan bentuk pertanyaan pilihan berganda dan pertanyaan terbuka.

\section{Pengolahan dan analisis data}

Pengolahan data dilakukan dengan menggunakan SPSS versi 19.00. Untuk mengetahui hubungan kebiasaan makan pagi dengan kejadian anemia, dilakukan pengujian statistik dengan uji Chi-Square pada tingkat kemaknaan $95 \%(\alpha<0,05)$.

\section{HASIL}

\section{Karakteristik responden penelitian}

Responden penelitian ialah murid sekolah SD Negeri 3 Manado kelas 4, 5, 6 yang berjumlah 83 orang dan berusia 9-12 tahun. Karakteristik responden meliputi usia, jenis kelamin, tingkat pendidikan orang tua dan pekerjaan orang tua (Tabel $1)$.

\section{Analisis univariat}

\section{Gambaran kebiasaan makan pagi}

Tabel 2 memperlihatkan bahwa murid SD kelas 4, 5, 6 di SD Negeri 3 Manado yang mempunyai kebiasaan makan pagi sebanyak 58 responden $(69,9 \%)$ dan yang tidak mempunyai kebiasaan makan pagi sebanyak 25 responden $(30,1 \%)$.

\section{Gambaran anemia}

Berdasarkan kriteria WHO 2001, dari 83 subjek penelitian terdapat 74 murid (89,2\%) dengan hemoglobin normal (tidak anemia) dan sembilan murid (10,8\%) tergolong anemia (Tabel 3).
Tabel 1. Karakteristik responden.

\begin{tabular}{|c|c|c|c|}
\hline \multicolumn{2}{|c|}{ Karakteristik responden } & \multirow{2}{*}{$\frac{n}{5}$} & \multirow{2}{*}{$\%$} \\
\hline Usia & 9 & & \\
\hline \multirow{4}{*}{ (tahun) } & 10 & 54 & 65,1 \\
\hline & 11 & 22 & 26,5 \\
\hline & 12 & 2 & 2,4 \\
\hline & & 83 & $100 \%$ \\
\hline \multirow{4}{*}{$\begin{array}{c}\text { Jenis } \\
\text { kelamin }\end{array}$} & & & \\
\hline & Laki-laki & 42 & 50,6 \\
\hline & Perempuan & 41 & 49,4 \\
\hline & & 83 & 100 \\
\hline \multirow{7}{*}{$\begin{array}{c}\text { Pendidikan } \\
\text { ayah }\end{array}$} & & & \\
\hline & SD & 7 & 8,4 \\
\hline & SLTP & 10 & 12 \\
\hline & SLTA & 36 & 43,4 \\
\hline & D3 & 14 & 16,9 \\
\hline & $\mathrm{S} 1 / \mathrm{S} 2 / \mathrm{S} 3$ & 16 & 19,3 \\
\hline & & 83 & $100 \%$ \\
\hline \multirow[t]{8}{*}{ Pendidikan } & & & \\
\hline & TT SD & 1 & 1,2 \\
\hline & SD & 4 & 4,8 \\
\hline & SLTP & 25 & 30,1 \\
\hline & SLTA & 37 & 44,6 \\
\hline & D3 & 5 & 6 \\
\hline & $\mathrm{S} 1 / \mathrm{S} 2 / \mathrm{S} 3$ & 11 & 13,3 \\
\hline & & 83 & $100 \%$ \\
\hline \multirow[t]{9}{*}{$\begin{array}{c}\text { Pekerjaan } \\
\text { ayah }\end{array}$} & PNS & 10 & 12 \\
\hline & Pegawai & & \\
\hline & swasta & 21 & 25,3 \\
\hline & Wiraswasta & 34 & 41 \\
\hline & ABRI & 2 & 2,4 \\
\hline & Polisi & 1 & 1,2 \\
\hline & Buruh/tukang & 8 & 9,6 \\
\hline & Sopir & 7 & 8,4 \\
\hline & & 83 & $100 \%$ \\
\hline \multirow{9}{*}{$\begin{array}{c}\text { Pekerjaan } \\
\text { ibu }\end{array}$} & & & \\
\hline & PNS & 6 & 7,2 \\
\hline & Pegawai & & \\
\hline & swasta & 7 & 8,4 \\
\hline & Wiraswasta & 9 & 10,8 \\
\hline & ABRI & 2 & 2,4 \\
\hline & Polisi & 2 & 2,4 \\
\hline & IRT & 57 & 68,7 \\
\hline & & 83 & $100 \%$ \\
\hline
\end{tabular}

Hubungan kebiasaan makan pagi dengan kejadian anemia pada murid SD Negeri 3 Manado

Untuk melihat hubungan kebiasaan makan pagi dengan kejadian anemia pada 
murid Sekolah Dasar Negeri 3 Manado, dilakukan pengujian statistik dengan menggunakan uji Fisher's Exact yang merupakan uji alternatif dari chi-square (Tabel 4).

Tabel 2. Distribusi responden berdasarkan kebiasaan makan pagi.

\begin{tabular}{lll}
\hline \multirow{2}{*}{ Kebiasaan Makan Pagi } & \multicolumn{2}{c}{ Jumlah } \\
\cline { 2 - 3 } & $\mathbf{n}$ & $\mathbf{\%}$ \\
\hline Tidak makan pagi & 25 & 30,1 \\
Makan pagi & 58 & 69,9 \\
\hline Total & $\mathbf{8 3}$ & $\mathbf{1 0 0 \%}$ \\
\hline
\end{tabular}

Tabel 3. Distribusi responden berdasarkan status anemia.

\begin{tabular}{lcc}
\hline Status Anemia & $\mathbf{N}$ & $\mathbf{\%}$ \\
\hline Anemia & 9 & 10,8 \\
Tidak anemia & 74 & 89,2 \\
\hline Total & $\mathbf{8 3}$ & $\mathbf{1 0 0 \%}$ \\
\hline
\end{tabular}

Tabel 4. Hasil analisis hubungan kebiasaan makan pagi dengan kejadian anemia.

\begin{tabular}{lcccc}
\hline \multirow{2}{*}{$\begin{array}{l}\text { Kebiasaan } \\
\text { Makan }\end{array}$} & \multicolumn{3}{c}{ Status Anemia } & \\
\cline { 2 - 4 } Pagi & Anemia & $\begin{array}{c}\text { Tidak } \\
\text { Anemia }\end{array}$ & Total & \\
& \multicolumn{5}{c}{$\begin{array}{c} \\
\text { Tidak }\end{array}$} & 6 & 19 & 25 & $\mathbf{0 , 0}$ \\
Ya & 3 & 55 & 58 & $\mathbf{1 9}$ \\
\hline
\end{tabular}

Tabel 4 menunjukkan jumlah responden yang memiliki dan tidak memiliki kebiasaan makan pagi serta jumlah responden yang anemia dan tidak anemia. Dari hasil uji statistik didapatkan nilai $P=0,019(\alpha<$ $0,05)$. Hal ini menunjukkan bahwa terdapat hubungan yang bermakna antara kebiasaan makan pagi dengan kejadian anemia pada murid SD Negeri 3 Manado.

\section{BAHASAN}

\section{Gambaran karakteristik penelitian}

Responden pada penelitian ini ialah murid SD Negeri 3 manado kelas 4, 5 dan 6 yang berjumlah 344 murid dan yang masuk dalam kriteria sampel penelitian sebanyak 83 murid. Berdasarkan karakteristik usia responden yang paling banyak ditemukan yaitu 54 murid $(65,1 \%)$ dengan kelompok usia 10 tahun. Kelompok usia ini sangat penting karena pada usia ini anak sangat rentan terhadap masalah pertumbuhan dan perkembangan. Dari 83 responden, yang terbanyak ialah anak laki-laki yaitu sebanyak 42 murid (50,6\%).

Tingkat pendidikan ayah dan ibu dari responden yang paling banyak ialah Sekolah Lanjutan Tingkat Atas (SLTA), dimana 36 orang ayah $(43,4 \%)$ dan 37 orang ibu $(44,6 \%)$. Dengan kata lain tingkat pendidikan orang tua dari responden adalah setara dan dapat diasumsikan bahwa sebagian besar para orang tau responden memiliki tingkat pengetahuan yang cukup.

Ditinjau dari distribusi menurut perkerjaan orang tua, $41 \%$ pekerjaan ayah adalah wiraswasta dan $68,7 \%$ pekerjaan ibu adah ibu rumah tangga (IRT). Pekerjaan wiraswasta merupakan pekerjaan yang tetap sehingga bisa dikatakan pendapatan mereka pun cukup untuk memenuhi kebutuhan keluarga. Dan dari jumlah presentasi dapat disimpulkan bahwa sebagian besar ibu dari murid SD Negeri 3 Manado tidak bekerja atau IRT.

\section{Gambaran anemia}

Dari hasil penelitian ini diperoleh hasil responden yang tergolong anemia 10,8\%, yaitu sembilan responden dan yang tidak anemia $89,2 \%$ yaitu 74 dari 83 responden. Responden yang tidak anemia lebih banyak dari pada yang anemia. Hal ini disebabkan oleh adanya tingkat kesadaran dan pemahaman yang cukup pada responden dalam mengkonsumsi makanan yang mengandung banyak zat besi.

Pada perempuan lebih banyak ditemukan anemia dari pada laki-laki. Hal ini disebabkan karena kebutuhan anak perempuan lebih besar dari pada anak laki-laki yaitu kebutuhan gizi pada anak perempuan akan meningkat pada saat masa pubertas. Pada masa pubertas anak perempuan akan mengalami menstruasi sekaligus adanya peningkatan kebutuhan zat besi. 


\section{Gambaran kebiasaan makan pagi}

Hasil penelitian kebiasaan makan pagi pada anak murid SD Negeri 3 manado sebanyak 83 anak, 58 responden yang mempunyai kebiasaan makan pagi. Sedangkan yang tidak terbiasa makan pagi sebanyak 25 responden. Hal ini menunjukkan bahwa tingkat pengetahuan tentang makan pagi serta kesadaran responden terhadap kebiasaan makan pagi sudah cukup baik.

Pendidikan yang rendah akan mempengaruhi pengetahuan gizi seseorang, hal ini akan mempengaruhi orang tersebut dalam pemilihan, cara pengolahan dan cara pengaturan menu makan, pada masyarakat yang berpendidikan rendah biasanya lebih banyak kepercayaan dan tahayul dalam makanan, dan biasanya lebih sulit untuk dirubah. Pendidikan dan sosial ekonomi yang rendah akan mempengaruhi kemampuan keluarga dalam mencari fasilitas pelayanan kesehatan. ${ }^{6}$

Sarapan memberi kontribusi besar kepada energi harian dan asupan nutrisi. Sarapan menyediakan $16 \%$ dari asupan energi harian anak-anak Selandia Baru, sekitar sepertiga dari kalsium, besi, tiamin, riboflavin dan asupan folat, dan seperlima asupan seng. Anak-anak yang melewatkan sarapan pagi memiliki asupan gizi secara signifikan lebih buruk setiap hari, termasuk asupan yang tinggi lemak total, dan asupan makanan rendah serat dan zat gizi mikro daripada mereka yang sarapan. Anak-anak kelaparan mungkin kekurangan energi dan motivasi untuk terlibat dalam kegiatan kelas, sementara kekurangan gizi dan kekurangan zat gizi mikro telah terbukti berdampak pada kesehatan fisik, mental, dan sosial, dan mengurangi fungsi kognitif. ${ }^{5}$

Pada penelitian ini diketahui bahwa adanya hubungan yang bermakna antara kebiasaan makan pagi dengan kejadian anemia pada murid SD Negeri 3 Manado. Peran makan pagi sangat berpengaruh terhadap tumbuh kembang anak. Hasil penelitian pada murid SD Negeri 3 Manado kelas 4, 5 dan 6 dilihat bahwa anak yang tidak memiliki kebiasaan makan pagi akan lebih mudah mengarah ke anemia diban- dingkan dengan anak yang memiliki kebiasaan makan pagi.

\section{SIMPULAN}

Berdasarkan hasil penelitian dan pembahasan, dapat disimpulkan Murid Sekolah Dasar Negeri 3 Manado sebesar 65,1\% memiliki kebiasaan makan pagi, berdasarkan pemeriksaan kadar hemoglobin sebagian besar murid Sekolah Dasar Negeri 3 Manado berada pada kategori normal atau tidak anemia $(89,2 \%)$, dan terdapat hubungan yang bermakna antara kebiasaan makan pagi dengan kejadian anemia pada murid SD Negeri 3 Manado.

\section{SARAN}

Disarankan kepada orang tua dan pihak sekolah agar tetap meningkatkan budaya makan pagi bagi murid sekolah, dan perlunya kerja sama lintas sektor terutama dengan puskesmas setempat untuk melakukan pemeriksaan kesehatan secara berkala pada anak sekolah seperti status gizi dan skrining anemia.

\section{DAFTAR PUSTAKA}

1. Azrul A. Kecenderungan Masalah Gizi dan Tantangan di Masa Depan [homepage on the Internet]. 2004 [cited 2011 Nov 13]. Available from: http:/gizi.depkes.go.id/makalah/Makalah \%20Dirjen-Sahid\%202.PDF.

2. de Benoist B, McLean E, Egli I, Cogswell M, editors. Worldwide Prevalence of anemia 1993-2005. WHO Global Database on Anemia Geneva, World Health Organization. 2008.

3. Almaitser S. Prinsip Dasar Ilmu Gizi, Jakarta: PT. Gramedia Pustaka Utama, 2009; p.250-265.

4. Arisman. Gizi Dalam Daur Kehidupan, Jakarta : EGC, 2010 ; p.171-179.

5. Ni Mhurchu. Effects of a free school breakfast programme on school attendance, achievement, psychosocial function, and nutrition: a stepped wedge cluster randomised trial. BioMed Central Public Health [serial online]. 2010 [cited 2011 Sep];10(738): p.1-6. 
58 Jurnal e-Biomedik (eBM), Volume 1, Nomor 1, Maret 2013, hlm. 53-58

6. Warren JM, Henry CJ, Simonite V. Low glycemic index breakfast and reduced food intake in preadolescent children. Pediatrics [serial online]. 2003 [cited $2011 \mathrm{Sep}$ ]; 112 (5): p. 414-9. 